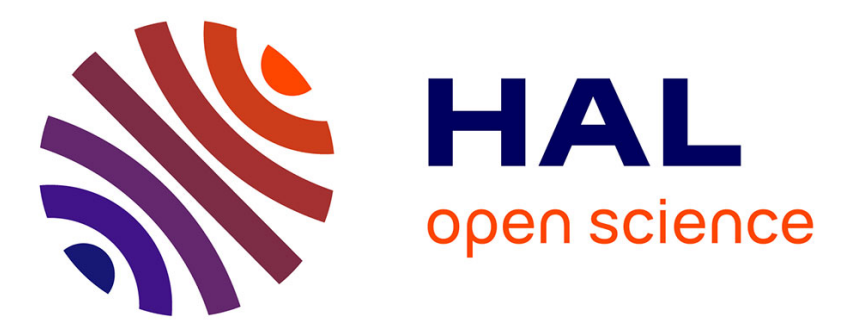

\title{
Impact of oak wood modalities on the (non)-volatile composition and sensory attributes of red wines
}

María Reyes González-Centeno, Pierre-Louis Teissedre, Kleopatra Chira

\section{To cite this version:}

María Reyes González-Centeno, Pierre-Louis Teissedre, Kleopatra Chira. Impact of oak wood modalities on the (non)-volatile composition and sensory attributes of red wines. OENO One, 2021, 55 (2), pp.285-299. 10.20870/oeno-one.2021.55.2.4673 . hal-03303930

\section{HAL Id: hal-03303930 \\ https://hal.inrae.fr/hal-03303930}

Submitted on 28 Jul 2021

HAL is a multi-disciplinary open access archive for the deposit and dissemination of scientific research documents, whether they are published or not. The documents may come from teaching and research institutions in France or abroad, or from public or private research centers.
L'archive ouverte pluridisciplinaire HAL, est destinée au dépôt et à la diffusion de documents scientifiques de niveau recherche, publiés ou non, émanant des établissements d'enseignement et de recherche français ou étrangers, des laboratoires publics ou privés.

\section{(c)(1)}

Distributed under a Creative Commons Attribution| 4.0 International License 


\title{
Impact of oak wood ageing modalities on the (non)-volatile composition and sensory attributes of red wines
}

\author{
E\& María Reyes González-Centeno ${ }^{1,2,3}$, Pierre-Louis Teissedre ${ }^{1,2}$ and Kleopatra Chira ${ }^{1,2,3^{*}}$ \\ ${ }^{1}$ Université de Bordeaux, ISVV, EA 4577, Enologie, 210 Chemin de Leysotte, 33140 Villenave d'Ornon, France \\ ${ }^{2}$ INRA, ISVV, USC 1366 Enologie, 210 Chemin de Leysotte, 33140 Villenave d'Ornon, France \\ 3 Tonnellerie Nadalié, 99 Rue Lafont, 33290 Ludon-Médoc, France \\ * * *orresponding author: kleopatra.chira@u-bordeaux.fr \\ Associate editor: Stamatina Kallithraka
}

\section{A B S T R A C T}

During fermentation or ageing of wines, oak wood is commonly used in form of barrels, casks or derived oak products (chips, winewoods, tankstaves, among others). It is well known that aroma, structure, astringency, bitterness, aromatic persistence and colour may change as a result of wine-wood contact. A full-scale experimentation was performed under different oak ageing conditions in order to evaluate colour, phenolic, aromatic and sensory differences among final red wines (9-months ageing). Oenological parameters and wine colour were not impacted by ageing modality. At the end of ageing, no differences were found in total phenolic and tannin contents. Regardless of the ageing modality, total content and profile of fruity volatiles were globally maintained with regard to control ( $\geq 86 \%)$. In contrast, the higher the surface of wine-wood contact per unit of wine volume, the greater the extraction of woody aromas. Thus, barrels led to wines with the highest level of woody aromas $(515-864 \mu \mathrm{g} / \mathrm{L})$, followed by cask modalities $(430-470 \mu \mathrm{g} / \mathrm{L})$. From a sensory point of view, descriptors highlighting the woody character of wine (vanilla, spicy) were enhanced in all oak-aged wines when compared to control. However, our results indicate that a masking effect of fruity aroma by oak wood did not occur, since all modalities were perceived as fruity as the control. Thus, each oak ageing modality may lead to wines with a different woody character, without no impact on fruity perception, allowing wineries to achieve the targeted aromatic profile, good structure and just the right balance between fruity and woody aromas.

KEYWOR DS

oak ageing, phenolic composition, fruity and woody aroma, sensory analysis, barrel, derived oak products 


\section{INTRODUCTION}

Ageing process stands out as a fundamental step in the production of quality wine, given the role it plays in improving its sensory attributes by stabilizing the colour, increasing the aromatic complexity and softening the sensations of astringency and bitterness. Nowadays, the use of oak wood for the ageing of alcoholic beverages, both wines and spirits, is widespread. Ageing in barrels or casks remains the favourite forms of oak usage for quality wine. Meanwhile, derived oak products such as chips, cubes, winewoods, blocks or tankstaves, among others, were also authorized for winemaking some years ago (CE 1507/2006), becoming a less cost effective alternative to produce wood-flavoured wines. Since both barrels and casks, as well as alternative oak products, are all available at different toasting levels, a wide range of ageing possibilities is nowadays provided by cooperages. This allows wineries to achieve wines with the targeted aromatic profile, good structure and body and just the right balance between fruity and woody character.

Some authors have addressed the impact of different wood-ageing modalities on wine quality. Nevertheless, most of these studies are first approaches mainly assessing only phenolic, aromatic or sensory differences between ageing in barrel and/or in stainless steel tanks (with or without chips or staves). Thus, a lack of simultaneous comparison with other ageing modalities is observed in the literature.

The oak impact on wine aroma and flavour primarily deals with the extraction of (non)-volatile compounds from wood into wine. It is well known that phenolic compounds from wood are implied in the co-pigmentation processes and contribute to the astringency, bitterness and roundness of the resulting wine (Castro-Vázquezet al., 2013). On the other hand, volatile constituents, already present in natural wood or resulting from ethanolysis and/or thermolysis of wood macromolecules (lignin, cellulose, hemicelluloses) act as precursors of the aromatic complexity of wood-aged wines. Thus, far from being a simple material for wooden containers, oak wood actively participates in wine maturation.

The transfer of these (non)-volatile compounds from wood into wine during ageing will depend on the potential extractable fraction initially present in wood, which in turn is influenced by wood species, geographical origin and processing (seasoning, toasting) in cooperage (del Álamo Sanza et al., 2004).

The point is how wine evolves, in terms of phenolic, aromatic and organoleptic characteristics, depending on the chosen oak ageing modality. To address this question, a full-scale experiment with oak wood products (barrels, casks, winewoods and tankstaves) from the same cooperage (same manufacture, same species and origin of wood) was conducted, in order to get a more reliable comparison among ageing modalities with regard to their impact on the (non)-volatile composition of wine, as well as on their sensory properties.

\section{MATERIALS AND METHODS}

\section{Red wine vinification and ageing modalities}

Merlot grapes (Vitis vinifera L.) were manually harvested, vinified and aged in Château Pierre de Montignac (AOC Médoc Cru Bourgeois, France) during the 2018 vintage. Saccharomyces cerevisiae yeast (Zymaflore $^{\circledR}$ Xpure, Laffort) was added to conduct alcoholic fermentation at $25-28{ }^{\circ} \mathrm{C}$. Then, wines underwent spontaneous malolactic fermentation for three weeks at a maintained temperature of $18-22{ }^{\circ} \mathrm{C}$. Both alcoholic and malolactic fermentations were performed in stainless steel tanks in contact with oak wood blocks (dose $4 \mathrm{~g} / \mathrm{L}, 1 / 3$ MT toasting and 2/3 MT+ toasting). At the end of the malolactic fermentation, oak wood blocks were removed and wine was transferred to different containers (barrel, cask, diamond concrete vat, tronconic concrete vat, stainless steel tank) for a 9 -months ageing.

Specifically, ten different ageing modalities were considered for the study (Table 1, two replicates/ modality). Apart from the wine matured in both stainless steel tank (control) and diamond concrete vat, ageing was performed in the presence of oak wood (Quercus petraea, French origin) in all the other cases. For this purpose, some ageing modalities used woody containers such as casks (54 mm of staves thickness) and barrels ( $22 \mathrm{~mm}$ of staves thickness), and other included derived oak products such as winewoods $(1000 \times 110 \times 12 \mathrm{~mm})$ or tankstaves $(940 \times 65 \times 12 \mathrm{~mm})$. Both casks and barrels, as well as all derived oak products, used in the present research were provided by Tonnellerie Nadalié (Ludon-Médoc, France).

Red wine was sampled at the end of the malolactic fermentation and after 9-months ageing for further phenolic, aromatic and sensory analyses. 


\section{General analyses}

\subsection{Enological parameters in wines}

A WineScan ${ }^{\mathrm{TM}}$ Flex (FOSS Analytical, Denmark) was used to measure $\mathrm{pH}$, alcoholic strength $(\%)$, and both volatile and titratable acidity (g eq $\mathrm{H}_{2} \mathrm{SO}_{4} / \mathrm{L}$ ) of wines, by Fourier Transform InfraRed spectroscopy (FTIR) (Miramont et al., 2019). The equipment was previously calibrated with wine samples analyzed by official OIV methods (OIV, 2016). Wine from all ageing modalities was evaluated in triplicate at each sampling point.

\subsection{Colour measurement}

Absorbance's at $420(\mathrm{~d} 420), 520$ (d520) and $620 \mathrm{~nm}$ (d620) was determined in triplicate under $1 \mathrm{~mm}$ optical way with a V-630 UV-Vis spectrophotometer (JASCO, Japan). Then, the colour intensity $(\mathrm{CI}, \mathrm{d} 420+\mathrm{d} 520+\mathrm{d} 620)$ and the hue (ratio d420/d520) were calculated (González-Centeno et al., 2019). CIELab coordinates were also measured.

\subsection{Total phenolics, total proanthocyanidins and total anthocyanins}

Spectrophotometric analyses were performed in triplicate for total phenolics, total proanthocyanidins and total anthocyanins determination in red wines. An automated microplate reader (FLUOstar $^{\circledR}$ Optima, BMG LabTech, France) was used for total phenolics measurement via the Folin Ciocalteu method, whereas the other ones were determined, by using the same UV-Vis equipment than chromatic parameters, through the Bate-Smith reaction (Ribereau-Gayon and Stonestreet, 1966) and the sodium bisulfite discoloration method (Ribereau-Gayon and Stonestreet, 1965), respectively. Experimental conditions and wine dilution were set as previously described by González-Centeno et al. (2016).

\section{Oak ellagitannin content of wines}

Ellagitannins fractionation of red wines was adapted from González-Centeno et al. (2016). Previous packageing of a column $(55 \mathrm{~mm} \times 25 \mathrm{~mm})$ with TSK HW 50F resin and subsequent equilibration with $\mathrm{H}_{2} \mathrm{O} / \mathrm{HCOOH}(996 / 4$, v/v), a wine sample $(20 \mathrm{~mL})$ was loaded and first washed with the acidic aqueous solvent $(100 \mathrm{~mL})$. Then, an acidic hydromethanolic solution $\left(\mathrm{H}_{2} \mathrm{O} / \mathrm{MeOH} / \mathrm{HCOOH}, \quad 298 / 698 / 4, \quad \mathrm{v} / \mathrm{v} / \mathrm{v}\right)$ was used until total discoloration of the liquid leaving the cartridge. The ellagitannin fraction was obtained after elution with an $\mathrm{H}_{2} \mathrm{O} /$ acetone/HCOOH $\quad(298 / 698 / 4) \quad$ solvent and evaporation under reduced pressure.

TABLE 1. Ageing modalities considered in this research.

\begin{tabular}{|c|c|c|c|c|c|}
\hline \multirow[b]{2}{*}{ Modality } & \multirow{2}{*}{$\begin{array}{l}\text { Container } \\
\text { volume } \\
(\mathrm{hL})\end{array}$} & \multicolumn{2}{|c|}{ Toasting } & \multirow{2}{*}{$\begin{array}{c}\text { Dose of derived } \\
\text { oak products } \\
\text { (units/hL wine) }\end{array}$} & \multirow{2}{*}{$\begin{array}{c}\text { Surface of } \\
\text { wine--wood } \\
\text { contact }\left(\mathrm{m}^{2} / \mathrm{hL}\right)\end{array}$} \\
\hline & & Container & $\begin{array}{c}\text { Derived oak } \\
\text { products }\end{array}$ & & \\
\hline Cask & 30 & MT & & & 0,30 \\
\hline Cask $+w w$ & 30 & MT & MT & 0,33 & 0.38 \\
\hline Diamond concrete vat & 20 & & & & \\
\hline Diamond concrete vat + ww & 20 & & MT & 1,1 & 0,28 \\
\hline Tronconic concrete vat + ww & 50 & & $\begin{array}{c}50 \% \mathrm{MT} \\
50 \% \mathrm{MT}+\end{array}$ & 0,8 & 0,20 \\
\hline Tronconic concrete vat + ts & 50 & & $\begin{array}{c}50 \% \mathrm{MT} \\
50 \% \mathrm{MT}+\end{array}$ & 1,36 & 0,20 \\
\hline Barrel $225 \mathrm{~L}$ & 2,25 & Assemblage MT & & & 0,90 \\
\hline Barrel 225 L plexi heads & 2,25 & Privilège LMT AA & & & 0,90 \\
\hline Barrel $500 \mathrm{~L}$ & 5 & Assemblage MT & & & 0,70 \\
\hline Stainless steel tank (control) & 10 & & & & \\
\hline
\end{tabular}

ww, winewoods. ts, tankstaves. MT, medium toasting (barrels, $57^{\circ} \mathrm{C}$ for $68 \mathrm{~min}$; winewoods, $180^{\circ} \mathrm{C}$ for $3 \mathrm{~h}$; tankstaves, $180^{\circ} \mathrm{C}$ for $2 \mathrm{~h} 30$ ). MT+, medium toasting plus (winewoods, $190^{\circ} \mathrm{C}$ for $3.5 \mathrm{~h}$; tankstaves, $190^{\circ} \mathrm{C}$ for $2 \mathrm{~h} 45$ ). LMT AA, light medium toasting with watering $\left(55^{\circ} \mathrm{C}\right.$ for $\left.40 \mathrm{~min}\right)$. 
The solid residue obtained was redissolved in $\mathrm{H}_{2} \mathrm{O} / \mathrm{HCOOH}(996 / 1,1 \mathrm{~mL})$ and filtered $(0.45 \mu \mathrm{m})$ prior to HPLC-DAD/QQQ analysis. This fractionation was conducted in duplicate for each wine sample.

Ellagitannin analysis was carried out on a HPLC-DAD system coupled to a 6460 Triple Quadrupole mass spectrometer fitted with a heated electrospray ionization probe (Agilent Technologies, Waldbronn, Germany). Elution conditions, flow rates, composition of the mobile phases, ionization and spectrometric parameters were adapted from Gadrat et al. (2021). Total ellagitannin results were expressed as equivalents of castalagin (mg castalagin eq./L wine).

\section{Anthocyanin and flavan-3-ol determination by HPLC}

Anthocyanin separation was performed in triplicate on an Agilent Nucleosil 100-5C18 column $(250 \mathrm{~mm} \times 4.0 \mathrm{~mm}, 5 \mu \mathrm{m})$ by using a Thermo-Accela HPLC instrument consisting of a UV-Vis detector (Accela PDA detector), an autosampler (Accela autosampler), and a quaternary pump (Accela 600 pump). The elution conditions, flow rate and composition of the mobile phases have been previously detailed by González-Centeno et al. (2017). Injected external standards and previous results were used to identify the anthocyanin 3-O-monoglucosides (delphinidin, Dp; cyanidin, Cy; petunidin, Pt; peonidin, Pn; and malvidin, Mlv), as well as the acetylated and $p$-coumaroylated forms of $\mathrm{Pn}$ and Mlv. Results were expressed as equivalents of Mlv-3-O-monoglucoside (mg Mlv eq./L wine).

Monomeric and oligomeric flavan-3-ols were analysed on a reversed-phase LiChrospher ${ }^{\circledR}$ 100 RP18 column $(250 \mathrm{~mm} \times 4 \mathrm{~mm}, 5 \mu \mathrm{m})$ by using a Thermo-Finnigan Surveyor HPLC system including an UV-Vis detector (Surveyor PDA Plus), a fluorescence detector (Surveyor FL Plus Detector), an autosampler (Surveyor autosampler Plus), and a quaternary pump (Surveyor MS pump Plus). The elution conditions, flow rate, composition of the mobile phases, UV-Vis and fluorescence parameters were adapted from González-Centeno et al. (2012). Identification and quantification of the main peaks (monomers $(+)$-catechin (C), and (-)-epicatechin (EC); oligomers B1, B2, B3 and B4) were conducted using external standard calibration. Results were expressed as equivalents of $(+)$-catechin (mg catechin eq./L wine).
For both anthocyanin and flavan-3-ol analyses, wines were filtered and injected directly, without prior treatment and/or dilution.

\section{Aromatic composition of wines: extraction and gas chromatography analysis}

Gas-chromatography methods published by Barbe and Bertrand (1996) and Antalick et al. (2010) were respectively applied to quantify woody and fruity aroma composition. Equipment and experimental conditions of the volatile extraction prior to gas-chromatographic analyses were considered as described by González-Centeno et al. (2016). Pure reference standards were also analysed to identify all target compounds and to build the calibration curves used to calculate both woody and fruity aroma profiles. All results were expressed in $\mu \mathrm{g} / \mathrm{L}$ wine.

Regarding the woody aroma, the following ions were used to identify the target compounds: vanillin, $\mathrm{m} / \mathrm{z} \quad 151 ;$ eugenol, $\mathrm{m} / \mathrm{z} \quad 164$; $\beta$-methyl- $\gamma$-octalactone, $\mathrm{m} / \mathrm{z} \quad 99 ;$ and $\mathrm{m} / \mathrm{z} \quad 83$ for the internal standard (dodecan-1-ol). Total woody aroma concentration was calculated as the addition of the individual content of the oak-related compounds analysed in the present research. In the case of fruity aroma, the selected ions were m/z 102 for ethyl propanoate and ethyl 2-methylbutanoate, $\mathrm{m} / \mathrm{z} 88$ for ethyl butanoate, ethyl hexanoate, ethyl decanoate, ethyl dodecanoate, ethyl isobutyrate and ethyl 3-methylbutanoate, $\mathrm{m} / \mathrm{z} 70$ for isoamyl acetate, $\mathrm{m} / \mathrm{z} 61$ for propyl acetate, and $\mathrm{m} / \mathrm{z} 56$ for isobutyl acetate, butyl acetate, and hexyl acetate.

\section{Sensory analysis}

Tasting session was conducted in a standard sensory-analysis chamber (ISO-8589, 1988), equipped with separate booths, an uniform source of lighting, absence of noise and distracting stimuli, and a maintained ambient temperature $\left(19-22^{\circ} \mathrm{C}\right)$. Standard black wine glasses (ISO-3591, 1997), covered with a Petri dish to minimize the escape of volatile compounds, were used.

Fifteen expert judges (12 females and three males) participated in the descriptive sensory analysis of the present research at the Institute of Vine and Wine Sciences (University of Bordeaux). A sequential monadic design was applied and tasting order of the wines from the ten ageing modalities was randomized among judges. Both orthonasal odour (fruity, smoky, vanilla, spicy) and wine taste were evaluated (aromatic persistence, palate volume, sweetness, bitterness, astringency). 
For scoring of all the sensory attributes, a ten-point scale ( $0=$ 'absence', $10=$ 'at maximum intensity') was implemented. Then, their intensity level was expressed as the mean value of all the judges.

\section{Statistical analysis}

Results were presented as mean values with their corresponding standard deviations and package $\mathrm{R}$ version 4.0.2 ( $\mathrm{R}$ Foundation for Statistical Computing, Wien, Austria) was used for statistical analysis. Normality and homoscedasticity of the residuals were assessed for all parameters, by using the Shapiro-Wilk test and Levene's test, respectively. The parametric ANOVA and Tukey tests were used to highlight the existence and degree of significant differences, when populations were normally distributed and presented homogeneity in variance. If not, those statistical analyses were replaced, respectively, by the non-parametric Kruskal-Wallis and pairwiseWilcox (with BH adjustment) tests. Results of sensory analysis were all standardized in order to remove the judge factor and to better outline differences among ageing modalities. Wines were considered as different for a probability $\leq 5 \%$.

\section{RESULTS AND DISCUSSION}

\section{Oenological and chromatic attributes of wines}

After malolactic fermentation, wine presented a $\mathrm{pH}$ of $3.6 \pm 0.0$, an alcohol strength of $14.0 \pm 0.1 \%$ vol., titratable and volatile acidities of $3.6 \pm 0.1$ and $0.3 \pm 0.0 \mathrm{~g}$ eq. $\mathrm{H}_{2} \mathrm{SO}_{4} / \mathrm{L}$ wine, respectively. After 9-months ageing, all these values remained the same regardless of the ageing modality.

With regard to the chromatic parameters of wines, colour intensity $(1.6 \pm 0.1 \mathrm{AU})$ and hue $(0.7 \pm 0.0 \mathrm{AU})$ were not impacted neither by the ageing time nor by the ageing modality. At 9-months ageing, CIELab coordinates (L* $6.7 \pm 0.1, a^{*} 35.6 \pm 0.2, b^{*} 11.3 \pm 0.2$ ) slightly decreased from values after malolactic fermentation $\left(L^{*} 7.6 \pm 0.1, a^{*} 37.6 \pm 0.2\right.$, b* $13.0 \pm 0.1$ ). Meanwhile, no colour differences were perceived by tasters during the visual evaluation of wines.

\section{Total phenolic, proanthocyanidin and anthocyanin content}

Total proanthocyanidin content remained constant regardless of the ageing time and modality. In contrast, a significant reduction of both total phenolic $(9-15 \%)$ and total anthocyanin
(39-62\%) contents in all wines was observed from the end of the malolactic fermentation to the end of the ageing period (Table 2). Control wine (stainless steel tank) showed the highest total anthocyanin decrease, followed by wines aged in barrel modalities (49-51\%). The microoxygenation properties of oak barrels might justify this behavior compared to the other ageing containers. Anthocyanin loss reflects the various degradation and/or polymerization reactions where these compounds are involved.

This phenolic and anthocyanin decrease during the ageing period has been previously described in the literature for a red Sangiovese wine aged in both stainless steel tanks and barrels of different volume (225 L, $1000 \mathrm{~L})$ for 11 months (Castellari et al., 2001), and for a red Spanish wine aged with oak chips or in oak barrels of different wood origin for five months (del Álamo-Sanza et al., 2004), among others.

Both studies suggested an anthocyanin content decrease over the ageing time, due to condensation reactions with proanthocyanidins and/or oxidative degradation.

With regard to total phenolics, only the wine aged in tronconic concrete vat with winewoods differed from control wine (stainless steel tank) at the end of ageing. Meanwhile, all wines presented total anthocyanin contents significantly greater than control after 9-months ageing. Indeed, a protective antioxydant effect of ellagitannins against anthocyanin oxidation has been highlighted when oak wood is present during wine ageing (Vivas and Glories, 1996).

It is important to point out that no differences in total phenolic and total anthocyanin values were reported among wines aged in the same type of container (cask, diamond concrete vat, tronconic concrete vat, or barrel). That means that the presence and/or type of derived oak products in the case of cask, diamond concrete vat and tronconic concrete vat modalities, as well as the volume and/or type of heads in barrels, did not influence the total phenolic and total anthocyanin concentrations in the resulting wines.

\section{Ellagitannin content}

The presence of oak wood blocks during MLF explains the ellagitannins amount $(5.2 \pm 0.1 \mathrm{mg}$ castalagin eq./L wine) extracted at the end of this oenological step (Table 2). All cask and barrel ageing modalities allowed, as expected, further ellagitannin extraction during ageing. 


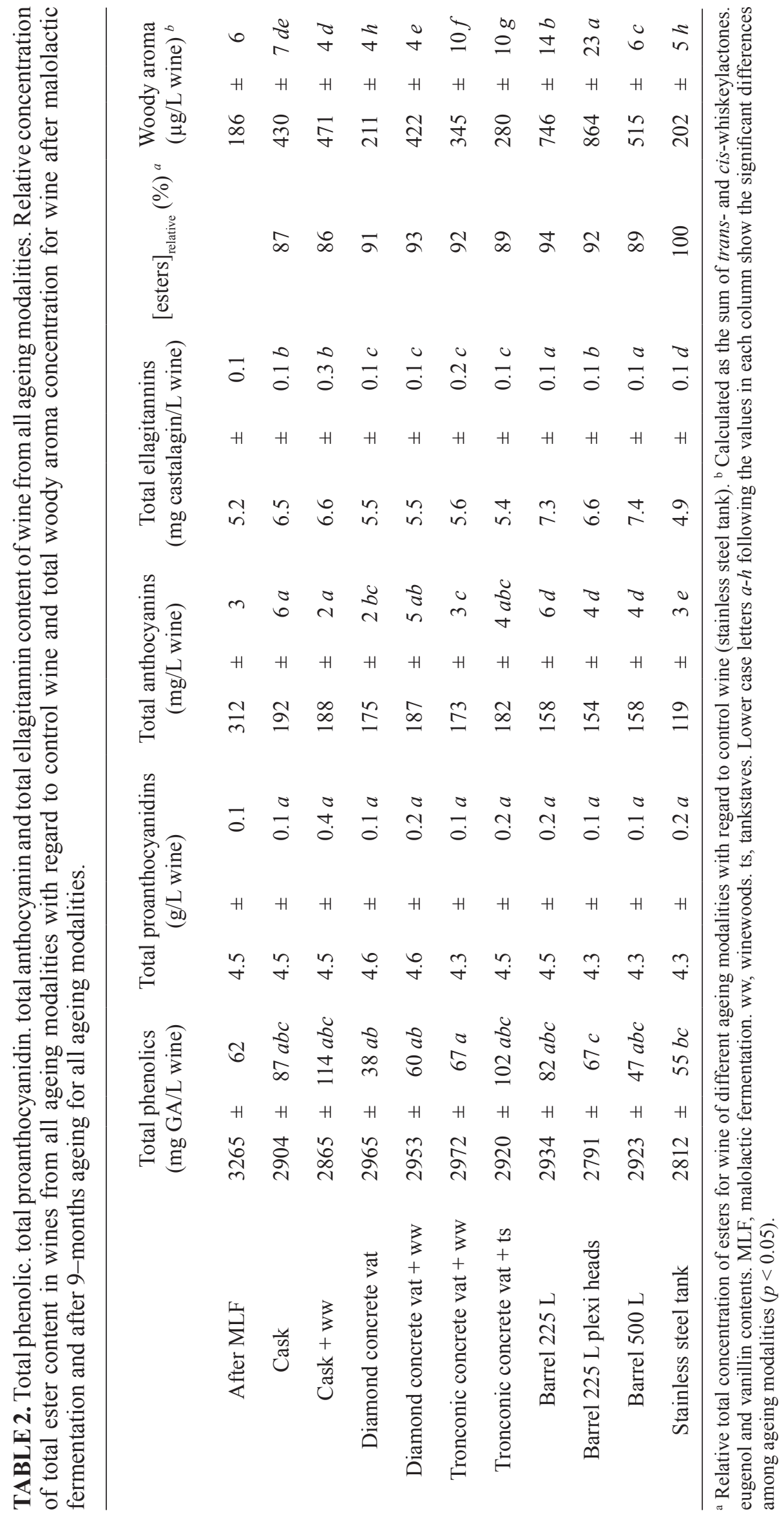




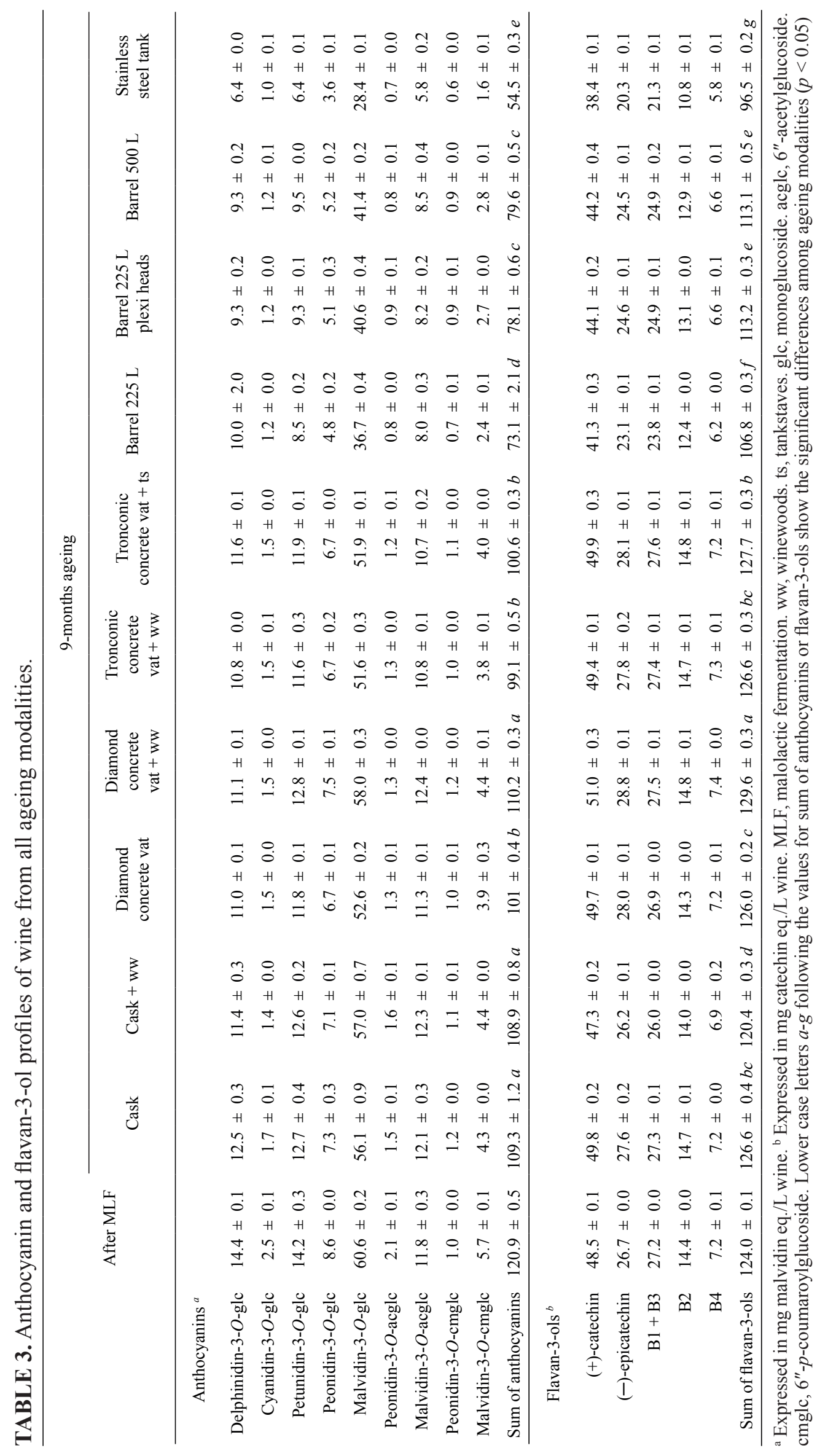


Specifically, 225L- and 500L-barrels showed $\sim 12 \%$ greater ellagitannin content than casks modalities and 225L-barrel with plexi heads. Differences on toasting conditions and on the ratio between the exposed wood area and the wine volume of these ageing modalities might justify their ellagitannin content. It has been stated in the literature that the higher the toasting intensity, the greater the thermal ellagitannin degradation (Chira and Teissedre, 2013a; Chira and Teissedre, 2013b; Chira and Teissedre, 2015; Jourdes et al., 2011; Navarro et al., 2016). Furthermore, watering process during toasting (applied to 225L-barrel with plexi heads modality) seems to diminish the wood ellagitannins pool to be transferred into wine (Chira and Teissedre, 2013a; Chira and Teissedre, 2013b; Chira and Teissedre, 2015; González-Centeno et al., 2017).

The increase of the ellagitannin content in wines as a result of wood contact during ageing has been previously noted by different authors (González-Centeno et al., 2016; Michel et al., 2013; Watrelot et al., 2018). And it is always much more important for barrel ageing than for wine aged with derived oak products (Frangipane et al., 2007; Jourdes et al., 2011).

\section{Anthocyanin and flavan-3-ol composition of wines}

Both profile and content of anthocyanins and flavan-3-ols in wines largely depend on the reactions occurring during wine maturation and ageing processes (Monagas et al., 2003; Moreno-Arribas et al., 2008). Anthocyanin and flavan-3-ol composition of all the wines investigated is depicted in Table 3. As observed, all ageing modalities kept the same anthocyanin and flavan-3-ol profile as wine after malolactic fermentation (MLF), but differed significantly in terms of content.

Wine matured in stainless steel tank showed the greatest loss of both anthocyanin and flavan-3-ol compounds at the end of ageing (9 months), just keeping $45 \%$ and $78 \%$ of initial anthocyanin and flavan-3-ol content (after MLF), respectively. Barrel modalities, due to micro-oxygenation phenomenon through wood pores and/or interaction with ellagitannins, held the second position in decline of those phenolic compounds during ageing: from 34 to $40 \%$ of initial anthocyanins and from 9 to $14 \%$ of initial flavan-3-ols. As previously observed for total anthocyanin content, cask, diamond concrete vat and tronconic concrete vat modalities exhibited a minor lessening of anthocyanins throughout ageing, and maintained their initial tannin content. The absence of micro-oxygenation and the lower ellagitannin transfer from wood to wine in those ageing modalities may explain this behavior. In fact, Oberholster et al. (2015) observed that a deliberate micro-oxygenation of red wine aged in stainless steel tanks for 6 months, with or without including derived oak products (chips or staves), may lead to a similar or even higher decrease of both flavan-3-ols and anthocyanins than barrel maturation.

Watrelot and Waterhouse (2018) showed similar anthocyanin declines after 12-months of barrel ageing (from 32 to $57 \%$ of loss of monomeric anthocyanins). Castellari et al. (2001) observed a greater anthocyanin and flavan-3-ol loss at the end of ageing (11 months in stainless steel tank, 225Land 1000 L-barrels), maintaining only $\sim 30 \%$ and $\sim 36 \%$ of the anthocyanin and flavan-3-ol contents before ageing.

General anthocyanin and flavan-3-ol trends persisted throughout all the ageing modalities considered in the present research. As expected, simple 3-O-glucosides were the most abundant anthocyanins (82-84 \% of the total anthocyanins quantified by HPLC), followed by the acetyl (11-14\% of the total anthocyanins quantified by HPLC), and, then, the $p$-coumaroyl (2-6\% of the total anthocyanins quantified by HPLC) glucosides. Within each anthocyanin family, malvidin forms showed the highest concentrations, being Mlv-3-O-glucoside the predominant one with concentrations ranging from 28.4 to $60.6 \mathrm{mg}$ Mlv eq./L wine.

With regard to the flavan-3-ol profile, the monomeric fraction was higher than the dimeric one for all wines, accounting for $\sim 61 \%$ of the total flavan-3-ols quantified. The (+)-catechin was the major monomer and the most abundant flavan-3-ol with concentrations ranging from 38.4 to $49.9 \mathrm{mg}(+)$-catechin eq./L wine. In wines from all the ageing modalities, (-)-epicatechin was the second main flavan-3-ol, oligomers B1, B2 and B3 displayed moderate values, whereas procyanidin B4 was present as a minor constituent, with concentrations representing $\sim 6 \%$ of the total flavan-3-ol content.

All these observations concerning the ranking order and distribution of both anthocyanin and flavan-3-ol compounds are in broad agreement with those previously reported in the literature (Chira et al., 2011; 
Fanzone et al., 2012; González-Centeno et al., 2017; González-Centeno et al., 2019; Hermosín-Gutiérrez et al., 2005; Monagas et al., 2003).

\section{Volatile composition of wines}

\subsection{Fruity aroma profile}

Fruity character of red wines is mainly determined by their ester profile. These volatile compounds are synthesized by yeasts during alcoholic fermentation from the precursors present in grapes, whose concentration directly depends on grape variety, terroir and both viticultural and oenological practices.

A total ester content of $\sim 1600 \mu \mathrm{g} / \mathrm{L}$ wine was quantified in wines from all ageing modalities, both at the end of malolactic fermentation and at the end of ageing. Relative concentration of total ester content was calculated after 9-months ageing (Table 2), to enhance comparison between control wine (stainless steel tank) and wine of each ageing modality. For this purpose, the wine aged in stainless steel tank was considered as the benchmark $(100 \%)$. According to the obtained results, total ester contents of all ageing modalities were, certainly, slightly lower than that observed in control wine. Nevertheless, all of them kept $\geq 86 \%$ of total ester concentration of control wine. Specifically, wine aged in barrel $225 \mathrm{~L}$ was the closest to control wine in terms of fruity volatiles concentration (94\%), followed by diamond concrete vat with winewoods $(93 \%)$ and barrel $225 \mathrm{~L}$ with plexi heads (92\%).

Relative concentration of each fruity volatile in wines from all ageing modalities was also calculated with regard to control wine (Figure 1). Among the ethyl esters of straight-chain fatty acids, only the ethyl decanoate, contributor to floral notes, was impacted by the ageing modality. As observed in Figure 1A, the other compounds from this ester family depicted similar concentrations in all wines.

Regarding the higher alcohol acetates (Figure 1B), concentration of isoamyl acetate, characterized by banana-like aroma, was the only to significantly diminish for all ageing modalities (from 9 to $19 \%)$ with regard to control wine.

Finally, no differences were found between control wine and wines from the different ageing modalities according to their profile of ethyl esters branched acids (Figure 1C).
Thus, according to the fruity aroma composition, both ethyl decanoate and isoamyl acetate are the main responsible of the above-mentioned slight decrease in total ester content. On the one hand, a perception threshold of $200 \mu \mathrm{g} / \mathrm{L}$ in young red wine is suggested for ethyl decanoate in the literature (Ferreira et al., 2000). Taking into account that all wines presented concentrations of this fruity volatile at subthreshold levels, ranging between 91 and $147 \mu \mathrm{g} / \mathrm{L}$ wine, differences among ageing modalities and with regard to control wine might to have no sensory direct impact on the overall fruity character of the resulting wines. On the other hand, isoamyl acetate was quantified in all wines at concentrations (232-366 $\mu \mathrm{g} / \mathrm{L}$ wine) well above its bibliographic perception threshold $(30 \mu \mathrm{g} / \mathrm{L}$ in young red wine) (Ferreira et al., 2000). In this case, it might be also suggested that there is no sensory direct impact on the fruity perception due to the different content of this volatile compound in wines from all ageing modalities.

According to these results, it is important to remark that both total content and profile of fruity aromas have not been modified significantly throughout ageing compared to control wine, regardless of the ageing modality. Consequently, the presence of oak wood during ageing did not cover the fruity volatile level of red wines.

\subsection{Woody aroma profile}

Oak wood ageing provides wine with aromatic compounds that will define its woody character. Among these volatiles, $\beta$-methyl- $\gamma$-octalactone, vanillin and eugenol are the main contributors to the overall oak wood aroma. While both isomers of $\beta$-methyl- $\gamma$-octalactone (whiskeylactones) are responsible for coconut, woody and oak-like notes, vanillin is related to vanilla smell, and eugenol to spicy and smoked flavours (Prida and Chatonnet, 2010).

Since initial wine performed both alcoholic and malolactic fermentations with oak wood blocks (see section 2.1), even ageing modalities that did not include oak wood exhibited a certain amount of woody volatiles at the end of ageing (Table 2). Therefore, both stainless steel tanks and diamond concrete vat displayed the lowest woody volatiles content ( $\sim 200 \mu \mathrm{g} / \mathrm{L}$ wine) corresponding to the extraction during the fermentation period.

For the other ageing modalities including oak wood, either as container material or added derived oak product, the extraction of woody volatiles is governed by the ratio between the exposed wood area and the wine volume. 

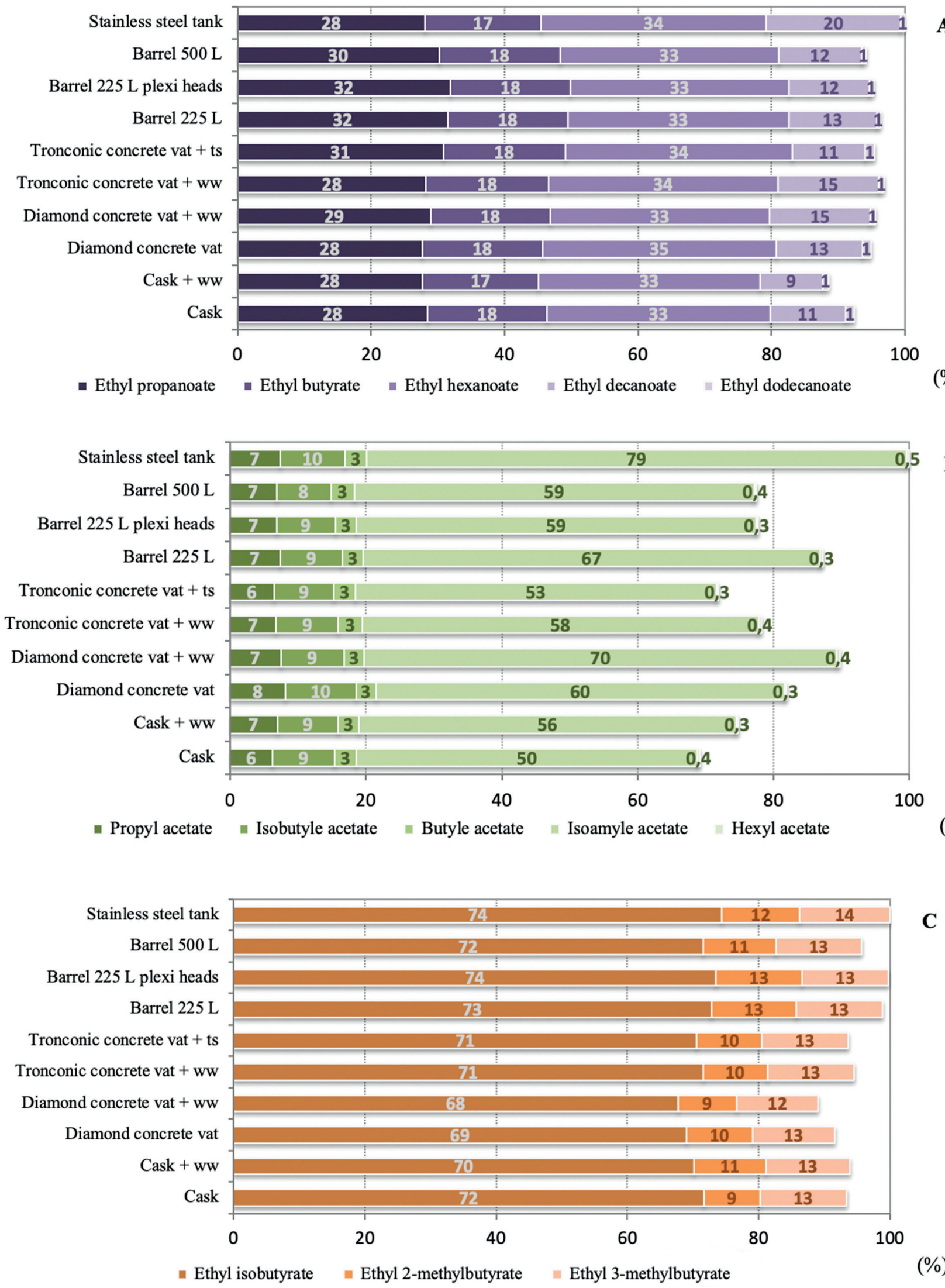

FIGURE 1. Relative concentration (\%) of fruity aromas (esters) for wine of different ageing modalities with regard to control wine (stainless steel tank, 100\%) after 9-months ageing: ethyl esters of straight-chain fatty acids (A), higher alcohol acetates (B), ethyl esters branched acids (C). ww, winewoods; ts, tankstaves. 


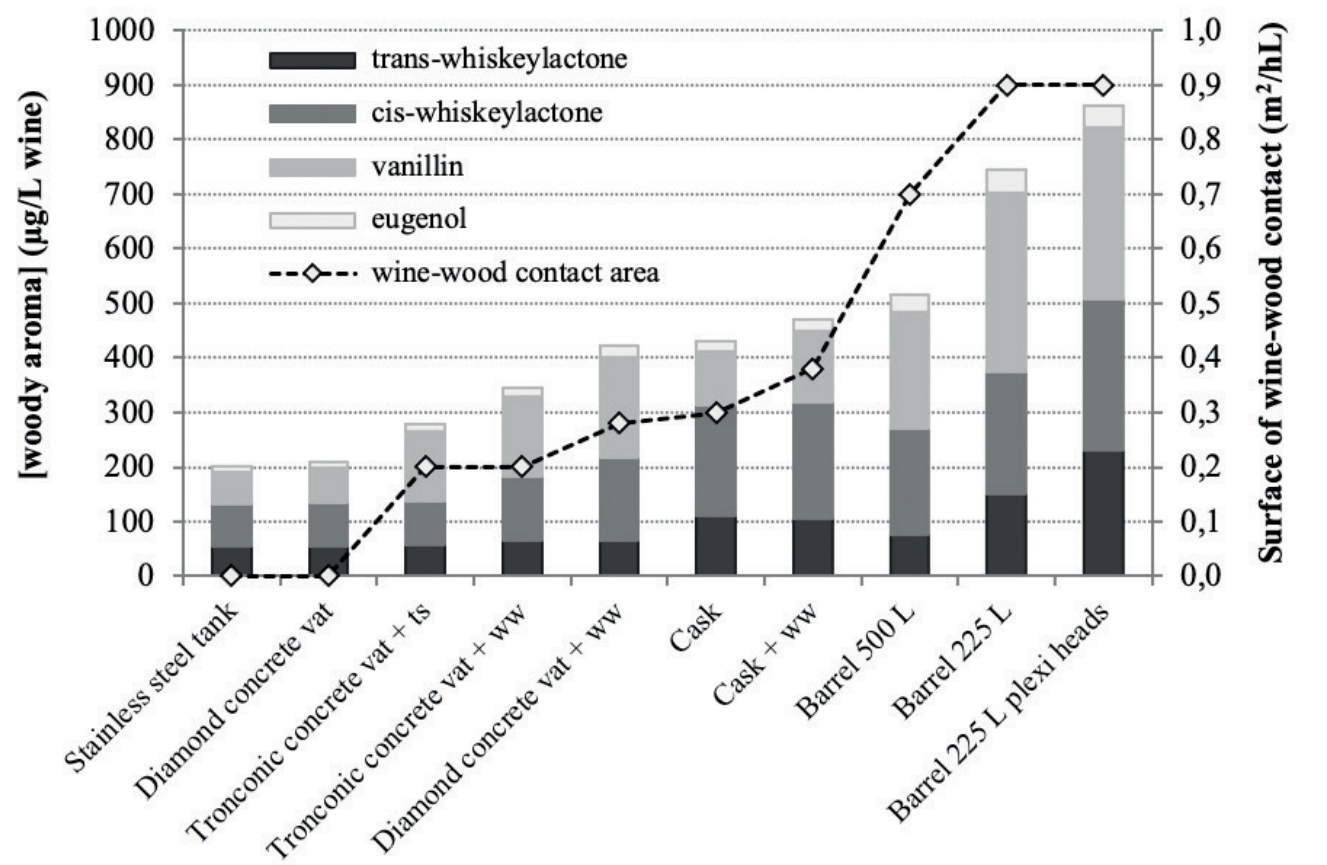

FIGURE 2. Woody aroma concentration ( $\beta$-methyl- $\gamma$-octalactone, vanillin, eugenol in $\mu \mathrm{g} / \mathrm{L}$ wine) for wine of different ageing modalities with regard to control wine (stainless steel tank) after 9-months ageing and surface of wine-wood contact $\left(\mathrm{m}^{2} / \mathrm{hL}\right)$ for each ageing modality. ww, winewoods; ts, tankstaves

The greater the surface of wood-wine contact per unit of wine volume, the higher the transfer of woody volatiles from wood into wine (Figure 2). Thus, wines aged in barrel modalities showed the greatest concentration of woody volatiles, followed by those matured in cask modalities, and then by those aged in non-woody containers with derived oak products.

Among barrels, those of $225 \mathrm{~L}$ presented the highest surface of wood-wine contact $\left(0.9 \mathrm{~m}^{2} / \mathrm{hL}\right.$ wine $)$, displaying the most important extraction rates of woody volatiles (Table 2). In the case of cask modalities, the presence of winewoods slightly increased the surface of wood-wine contact, and, consequently, the final total content of woody aromas in wine. Nevertheless, concentration differences were not statistically significant $(p>0.05)$. With regard to tronconic concrete vats, the surface of wood-wine contact was the same in both modalities $\left(0.2 \mathrm{~m}^{2} / \mathrm{hL}\right.$ wine). Furthermore, both winewoods and tankstaves presented the same medium toasting. Nonetheless, extraction and transfer of woody volatiles from winewoods into wine seems to be much more important than from tankstaves.

As expected, ageing modalities using woody containers (casks and barrels) showed a marked and progressive extraction of woody volatiles throughout the whole ageing period. Indeed, ageing modalities using derived oak products also extracted woody volatiles, but in a lesser extent. After 9-months ageing, both trans-whiskeylactone and eugenol were present at concentrations well below their perception thresholds $(370 \mu \mathrm{g} / \mathrm{L}$ for trans-whiskeylactone and $500 \mu \mathrm{g} / \mathrm{L}$ for eugenol) in all wines. In the case of vanillin, subthreshold levels $(320 \mu \mathrm{g} / \mathrm{L})$ were displayed by all ageing modalities except for barrels $225 \mathrm{~L}$ with both wood and plexi heads. When comparing wines from those barrel modalities to control wine, vanillin content was $\sim 5.7-$ fold times higher at the end of ageing.

In contrast with the other woody volatiles, cis-whiskeylactone was already extracted at concentrations beyond its perception threshold $(54 \mu \mathrm{g} / \mathrm{L})$ after malolactic fermentation in all wines considered. It is worth noting that this initial content of cis-whiskeylactone remained almost constant throughout the whole ageing period in wines from ageing modalities that did not include oak wood (stainless steel tanks and diamond concrete vat), as well as in wine aged in tronconic concrete vat with tankstaves. When comparing control wine to the rest of ageing modalities, cis-whiskeylactone content was $\sim 2.6$-fold times higher in wines aged in casks, $\sim 1.7-$ fold times greater in wines matured in both diamond and tronconic concrete vats with winewoods, and between 2.5- and 3.5-fold times higher in wines aged in barrels. 

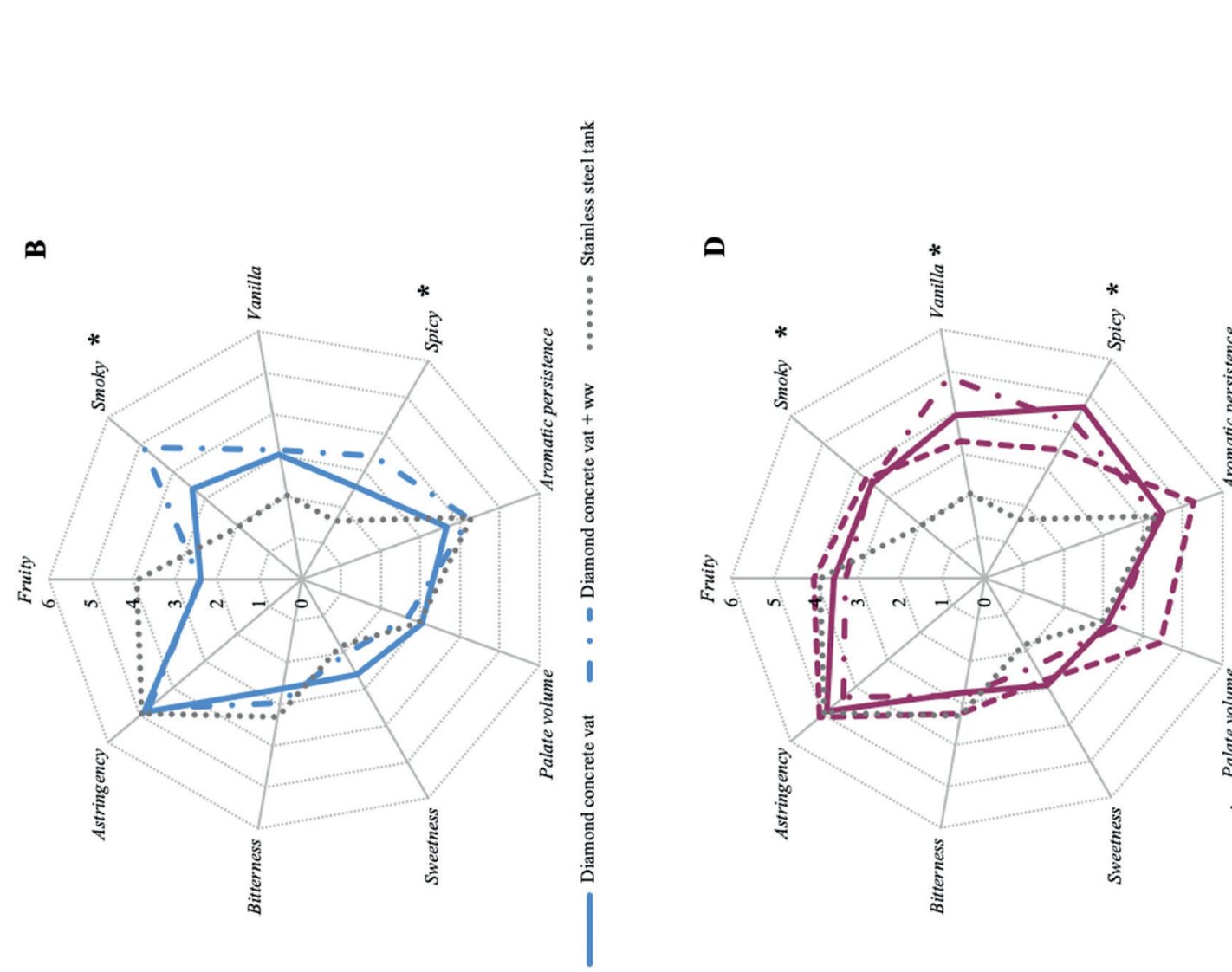

范
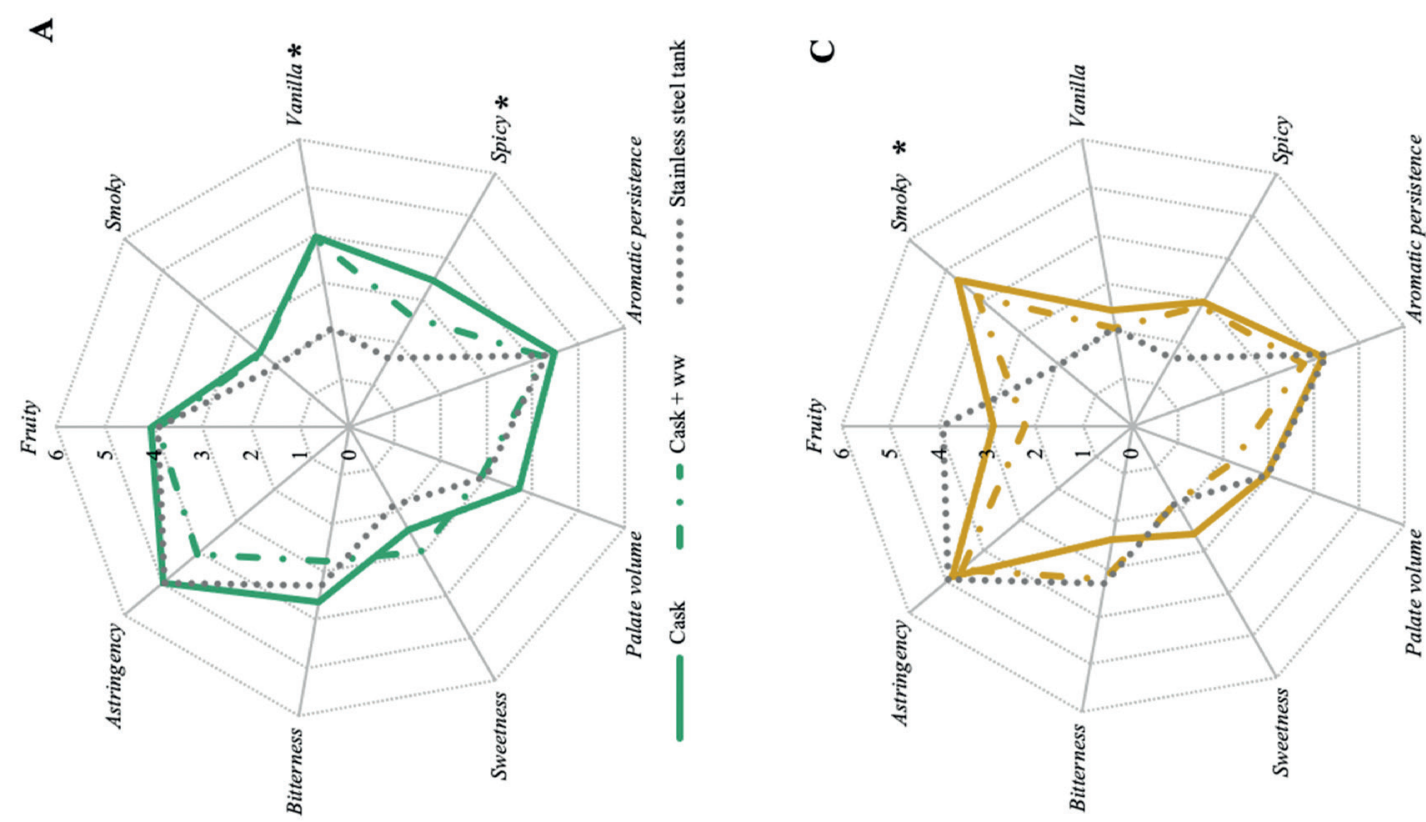
To the authors' knowledge, there is scarce scientific literature about the comparison of extraction rate of woody volatiles from oak wood used under different forms (barrel, staves, chips...) during wine ageing. Fernández de Simón et al. (2010a), Fernández de Simón et al. (2010b) and Dumitriu et al. (2020) revealed greater whiskeylactones, vanillin and/or eugenol contents for wines aged with oak staves during 3-6 months than when oak chips were used. Other studies have investigated the interest of using derived oak products when wine ageing is performed in old barrels in order to get a higher release of the targeted woody volatiles (Bautista-Ortín et al., 2008; Frangipane et al., 2007).

\section{Sensory analysis of wines}

Spider web diagrams obtained from average values of both olfactory and gustative descriptors from descriptive sensory analysis of wines matured under different ageing modalities for 9 months are depicted in Figure 3. For a better visualization of the results, sensory profiles of all wines aged in the same container (cask, diamond concrete vat, tronconic concrete vat or barrel) have been compared to that of control wine (stainless steel tank).

Regardless of the presence or not of winewoods, judges highlighted a higher vanilla flavour in wines from both cask modalities than in control wine. Furthermore, wine aged in cask was described as more spicy. In the case of diamond concrete vat modalities, the absence of winewoods during ageing lead to a wine perceived as not organoleptically different from control wine. Meanwhile, when winewoods were added, resulting wines were described as more smoky and more spicy. With regard to tronconic concrete vat modalities, regardless of the type of derived oak product used, wines were perceived as more smoky than control. Meanwhile, the use of either winewoods or tankstaves did not lead to organoleptic differences between both tronconic concrete vat modalities. Finally, wines aged in barrel modalities were all described to have higher smoky, vanilla and spicy flavours than control wine. Furthermore, a significantly greater palate volume was noted for wines aged in the largest size barrels $(500 \mathrm{~L})$.

According to these results, descriptors linked to overall oak character of wines (vanilla, smoky, spicy) are essentially the responsible for sensory differences among ageing modalities considered.
Globally, aromatic persistence, sweetness, bitterness and astringency descriptors were not impacted by ageing modality. Furthermore, wines from all ageing modalities were perceived as fruity as the control wine. For wines aged in both diamond and tronconic concrete vats, some differences in fruity perception were noted with regard to control wine, but they were not statistically significant $(p>0.05)$. Thus, the overall fruity aroma intensity has not been dominated by the overall woody aroma.

\section{CONCLUSIONS}

Phenolic and aromatic evolution of a red wine under different oak ageing conditions has been evaluated. Wine matrix (oenological and chromatic parameters, phenolic fraction) has not been influenced significantly either by the ageing container or the derived oak products used. Fruity perception was not dominated by the woody volatile fraction provided by oak wood during ageing as all. In fact, all oak aged wines were perceived as fruity as wine aged in stainless steel tanks. It was the woody aroma and the ellagitannin content that made the difference among final aged red wines. The higher the surface of wine-wood contact per unit of wine volume, the greater the extraction of both woody aromas and ellagitannins. Each ageing modality led to a particular content and profile of woody volatiles, highlighting as a consequence a different woody character in wines after 9-months ageing. Specifically, compared to control wine, significantly higher vanilla and spicy flavours were perceived in wines from cask modalities; the addition of derived oak products (winewoods, tankstaves) in both diamond or tronconic concrete vats led to wines described as more spicy and/or more smoky by the panel. And generally, greater smoky, vanilla and spicy flavours were highlighted for all wines aged in barrels.

Thus, the wide range of oak ageing products (barrels, casks and derived oak products) provided by cooperages may increase wine complexity due to attributes provided by oak wood, by preserving a good structure and their whole fruity potential.

Acknowledgements: The authors gratefully acknowledge Tonnellerie Nadalié cooperage (Ludon-Médoc, France) for providing all oak ageing modalities (casks, barrels, winewoods, tankstaves). They also thank Château Montignac for supplying the wine samples, as well as the judges who participated in the sensory analyses. 


\section{REFERENCES}

Antalick, G., Perello, M.-C., \& de Revel, G. (2010). Development, validation and application of a specific method for the quantitative determination of wine esters by headspace-solid-phase microextraction-gas chromatography-mass spectrometry. Food Chemistry, 121(4), 1236-1245. https://doi.org/10.1016/j. foodchem.2010.01.011

Barbe, J.C., \& Bertrand, A. (1996). Quantitative analysis of volatile compounds stemming from oak wood. Application to the ageing of wines in barrels. Journal of Cooperage Science and Technology, 2, 83-88.

Bautista-Ortín, A.B., Lencina, A.G., Cano-López, M., Pardo-Mínguez, F., López-Roca, J.M., \& Gómez-Plaza, E. (2008). The use of oak chips during the ageing of a red wine in stainless steel tanks or used barrels: Effect of the contact time and size of the oak chips on aroma compounds. Australian Journal of Grape and Wine Research, 14(2), 63-70. https://doi.org/10.1111/j.17550238.2008.00008.x

Castellari, M., Piermattei, B., Arfelli, G., \& Amati, A. (2001). Influence of ageing conditions on the quality of red Sangiovese wine. Journal of Agricultural and Food Chemistry, 49(8), 3672-3676. https://doi.org/10.1021/ jf010101w

Castro-Vázquez, L., Alañón, M.E., Ricardo-da-Silva, J.M., Pérez-Coello, M.S., \& Laureano, O. (2013). Evaluation of Portuguese and Spanish Quercus pyrenaica and Castanea sativa species used in cooperage as natural source of phenolic compounds. European Food Research and Technology, 237(3), 367-375. https://doi. org/10.1007/s00217-013-1999-5

Chira, K., Pacella, N., Jourdes, M., \& Teissedre, P.L. (2011). Chemical and sensory evaluation of Bordeaux wines (Cabernet-Sauvignon and Merlot) and correlation with wine age. Food Chemistry, 126(4), 1971-1977. https://doi.org/10.1016/j.foodchem.2010.12.056

Chira, K., \& Teissedre, P.L. (2013a). Extraction of oak volatiles and ellagitannins compounds and sensory profile of wine aged with French winewoods subjected to different toasting methods: Behaviour during storage. Food Chemistry, 140(1-2), 168-177. https:// doi.org/10.1016/j.foodchem.2013.02.049

Chira, K., \& Teissedre, P.L. (2013b). Relation between volatile composition, ellagitannin content and sensory perception of oak wood chips representing different toasting processes. European Food Research and Technology, 236(4), 735-746. https://doi.org/10.1007/ s00217-013-1930-0

Chira, K., \& Teissedre, P.L. (2015). Chemical and sensory evaluation of wine matured in oak barrel: effect of oak species involved and toasting process. European Food Research and Technology, 240(3), 533-547. https://doi.org/10.1007/s00217-014-2352-3

del Álamo Sanza, M., Nevares Domínguez, I., Cárcel Cárcel, L.M., \& Navas Gracia, L. (2004). Analysis for low molecular weight phenolic compounds in a red wine aged in oak chips. Analytica Chimica Acta, 513(1), 229-237. https://doi.org/10.1016/j.aca.2003.11.041

del Álamo-Sanza, M., Fernández Escudero, J.A., \& De Castro Torío, R. (2004). Changes in phenolic compounds and colour parameters of red wine aged with oak chips and in oak barrels. Food Science and Technology International, 10(4), 233-241. https://doi. org/10.1177/1082013204046095

Dumitriu, G.D., Peinado, R.A., Cotea, V.V., \& López de Lerma, N. (2020). Volatilome fingerprint of red wines aged with chips or staves: Influence of the ageing time and toasting degree. Food Chemistry, 310, Article ARTN 125801. https://doi.org/10.1016/j. foodchem.2019.125801

Fanzone, M., Zamora, F., Jofre, V., Assof, M., Gómez-Cordovés, C., \& Peña-Neira, A. (2012). Phenolic characterisation of red wines from different grape varieties cultivated in Mendoza province (Argentina). Journal of the Science of Food and Agriculture, 92(3), 704-718. https://doi.org/10.1002/ jsfa. 4638

Fernández de Simón, B., Cadahía, E., del Alamo, M., \& Nevares, I. (2010a). Effect of size, seasoning and toasting in the volatile compounds in toasted oak wood and in a red wine treated with them. Analytica Chimica Acta, 660(1-2), 211-220. https://doi.org/10.1016/j. aca.2009.09.031

Fernández de Simón, B., Cadahía, E., Muiño, I., Del Álamo, M., \& Nevares, I. (2010b). Volatile composition of toasted oak chips and staves and of red wine aged with them. American Journal of Enology and Viticulture, 61(2), 157-165.

Ferreira, V., López, R., \& Cacho, J. F. (2000). Quantitative determination of the odorants of young red wines from different grape varieties. Journal of the Science of Food and Agriculture, 80(11), 1659-1667. https://doi.org/10.1002/10970010(20000901)80:11<1659::aid-jsfa693>3.0.co;2-6

Frangipane, M.T., De Santis, D., \& Ceccarelli, A. (2007). Influence of oak woods of different geographical origins on quality of wines aged in barriques and using oak chips. Food Chemistry, 103(1), 46-54. https://dx.doi.org/10.1016/j.foodchem.2006.07.070

Gadrat, M., Lavergne, J., Emo, C., Teissedre, P.L., \& Chira, K. (2021). Validation of a mass spectrometry method to identify and quantify ellagitannins in oak wood and cognac during ageing in oak barrels. Food Chemistry, 342, Article 128223. https://doi. org/10.1016/j.foodchem.2020.128223

González-Centeno, M.R., Chira, K., \& Teissedre, P.L. (2017). Comparison between malolactic fermentation container and barrel toasting effects on phenolic, volatile, and sensory profiles of red wines. Journal of Agricultural and Food Chemistry, 65, 3320-3329. https://doi.org/10.1021/acs.jafc.6b05497 
González-Centeno, M.R., Chira, K., Miramont, C., Escudier, J.L., Samson, A., Salmon, J.M., Ojeda, H., \& Teissedre, P.L. (2019). Disease resistant Bouquet vine varieties: assessment of the phenolic, aromatic, and sensory potential of their wines. Biomolecules, 9(12), Article ARTN 793. https://doi.org/10.3390/ biom9120793

González-Centeno, M.R., Chira, K., \& Teissedre, P.L. (2016). Ellagitannin content, volatile composition and sensory profile of wines from different countries matured in oak barrels subjected to different toasting methods. Food Chemistry, 210, 500-511. https://doi. org/10.1016/j.foodchem.2016.04.139

González-Centeno, M.R., Jourdes, M., Femenia, A., Simal, S., Rosselló, C., \& Teissedre, P.L. (2012). Proanthocyanidin composition and antioxidant potential of the stem winemaking byproducts from 10 different grape varieties (Vitis vinifera L.). Journal of Agricultural and Food Chemistry, 60(48), 1185011858. https://doi.org/10.1021/jf303047k

Hermosín-Gutiérrez, I., Sánchez-Palomo Lorenzo, E., \& Vicario Espinosa, A. (2005). Phenolic composition and magnitude of copigmentation in young and shortly aged red wines made from the cultivars, Cabernet Sauvignon, Cencibel, and Syrah. Food Chemistry, 92(2), 269-283. https://doi.org/10.1016/j. foodchem.2004.07.023

Jourdes, M., Michel, J., Saucier, C., Quideau, S., \& Teissedre, P.L. (2011). Identification, amounts, and kinetics of extraction of $C$-glucosidic ellagitannins during wine ageing in oak barrels or in stainless steel tanks with oak chips. Analytical and Bioanalytical Chemistry, 401(5), 1531-1539. https://doi.org/10.1007/ s00216-011-4949-8

Michel, J., Jourdes, M., Le Floch, A., Giordanengo, T., Mourey, N., \& Teissedre, P.L. (2013). Influence of wood barrels classified by NIRS on the ellagitannin content/ composition and on the organoleptic properties of wine. Journal of Agricultural and Food Chemistry, 61(46), 11109-11118. https://doi.org/10.1021/jf403192y

Miramont, C., Jourdes, M., Selberg, T., Juhl, H.V., Norgaard, L., \& Teissedre, P.L. (2019). Prediction of anthocyanin concentrations during red wine fermentation: development of Fourier transform infrared spectroscopy partial least squares models. Oeno One, 53(4), 681-694. https://doi.org/10.20870/ oeno-one.2019.53.4.2577

Monagas, M., Gómez-Cordovés, C., Bartolomé, B., Laureano, O., \& Ricardo-Da-Silva, J.M. (2003). Monomeric, oligomeric, and polymeric flavan-3-ol composition of wines and grapes from Vitis vinifera $\mathrm{L}$. cv. Graciano, Tempranillo, and Cabernet Sauvignon. Journal of Agricultural and Food Chemistry, 51(22), 6475-6481. https://doi.org/10.1021/jf030325+

Moreno-Arribas, M.V., Gómez-Cordovés, C., \& Martín-Álvarez, P.J. (2008). Evolution of red wine anthocyanins during malolactic fermentation, postfermentative treatments and ageing with. Food Chemistry, 109(1), 149-158. https://doi.org/10.1016/j. foodchem.2007.12.040

Navarro, M., Kontoudakis, N., Gómez-Alonso, S., García-Romero,E.,Canals,J.M.,Hermosín-Gutiérrez,I., \& Zamora, F. (2016). Influence of the botanical origin and toasting level on the ellagitannin content of wines aged in new and used oak barrels. Food Research International, 87, 197-203. https://doi.org/10.1016/j. foodres.2016.07.016

Oberholster, A., Elmendorf, B.L., Lerno, L.A., King, E.S., Heymann, H., Brenneman, C.E., \& Boulton, R.B. (2015). Barrel maturation, oak alternatives and micro-oxygenation: Influence on red wine ageing and quality. Food Chemistry, 173, 12501258. https://doi.org/10.1016/j.foodchem.2014.10.043

OIV (2016). Compendium of International Methods of Analysis of Wines and Musts (2016 ed.).

Prida, A., \& Chatonnet, P. (2010). Impact of oak-derived compounds on the olfactory perception of barrel-aged wines. American Journal of Enology and Viticulture, 61(3), 408-413.

Ribereau-Gayon, P., \& Stonestreet, E. (1965). Le dosage des anthocyanes dans le vin rouge. Bulletin de la Société Chimique de France, 9, 2649-2652.

Ribereau-Gayon, P., \& Stonestreet, E. (1966). Dosage des tanins du vin rouge et détermination de leur structure. Chimie Analytique, 48(4), 188-196.

Vivas, N., \& Glories, Y. (1996). Role of oak wood ellagitannins in the oxidation process of red wines during ageing. American Journal of Enology and Viticulture, 47(1), 103-107.

Watrelot, A.A., Badet-Murat, M.L., \& Waterhouse, A.L. (2018). Oak barrel tannin and toasting temperature: Effects on red wine condensed tannin chemistry. LWTFood Science and Technology, 91, 330-338. https://doi. org/10.1016/j.lwt.2018.01.065

Watrelot, A.A., \& Waterhouse, A.L. (2018). Oak barrel tannin and toasting temperature: Effects on red wine anthocyanin chemistry. LWT-Food Science and Technology, 98, 444-450. https://doi.org/10.1016/j. lwt.2018.09.025 